Página inicial: 370 - Página Final: 386

Tipo de artículo: Investigación.

\title{
Desplazamiento forzado y empoderamiento femenino: el caso de la presa Picachos en el sur de Sinaloa, México
}

\author{
Forced Displacement and Women's Empowerment: The Case of Picachos Dam in the \\ Southern Region of Sinaloa, Mexico
}

Recibido: abril de 2017 Revisado: mayo de $2017 \quad$ Aceptado: junio de 2017

Por: Sibely Cañedo-Cázarez ${ }^{1} \&$ Juan Manuel Mendoza-Guerrero ${ }^{2}$

${ }^{1}$ Maestra en Ciencias, estudiante de Doctorado en Ciencias Sociales por la Universidad Autónoma de Sinaloa. México. Contacto: sibely.canedo@gmail.com ORCID:

http://orcid.org/0000-0002$\underline{7458-2627}$

${ }^{2}$ Doctor en Historia de la Frontera por la Universidad de Texas, Profesor e Investigador de tiempo completo de la Facultad de Ciencias Sociales de la Universidad Autónoma de Sinaloa. Profesor investigador de la Universidad Autónoma de Sinaloa. México. Contacto:

jumamegue@uas.edu.mx ORCID:

http://orcid.org/0000-0002$\underline{1293-5749}$

\section{Resumen}

A través de la resistencia es posible dar un nuevo sentido a las representaciones sociales de género, creando relatos alternos a la victimización de comunidades desplazadas. El objetivo es exponer un caso de empoderamiento femenino, como respuesta a la experiencia del desplazamiento forzado. Es la historia de San Marcos en el municipio de Mazatlán, al sur del estado de Sinaloa, México. Uno de los seis pueblos inundados por la presa Picachos, cuya construcción a partir de 2006 detonó un largo conflicto entre comuneros y gobierno estatal.

Palabras clave. Desplazamiento forzado; empoderamiento femenino; presa Picachos; representaciones de género.

\begin{abstract}
Through resistance it is possible to give a new sense to social gender representations, creating alternative accounts to the victimization of displaced communities. The objective is to present a Women's Empowerment case, as a response to the forced displacement experience. This is the history of San Marcos in the Municipality of Mazatlan, in the south of the State of Sinaloa, Mexico. One of the six flooded towns by Picachos Dam, whose building as of 2006, triggered a long conflict between commoners and the state government.
\end{abstract}

Key words: Forced Displacement; Women's Empowerment; Picachos Dam; Gender Representations. 


\section{Introducción}

Si bien es cierto que la construcción de infraestructura hidráulica ha hecho contribuciones importantes a la economía mundial y a la producción de alimentos, fomentan un crecimiento desigual cuyos costos sociales, humanos y culturales son inaceptables en un gran número de casos. Pero dentro de las afectaciones hay grupos vulnerables que padecen estos costos de forma desproporcionada, entre ellos se cuentan indígenas, campesinos, personas con discapacidades, niños y mujeres, quienes además de soportar una mayor carga en el proceso de reasentamiento, resultan menos beneficiados por los recursos generados con la construcción de los embalses (CMR, 2000).

Dentro de estos grupos, el abordaje de una perspectiva de género resulta significativo para lograr un salto cualitativo en el orden social de las comunidades, por lo que, se resalta que, la participación activa de las mujeres en los movimientos sociales puede contribuir a modificar las representaciones de género, que tienden a victimizar y a poner en desventaja al sector femenino de la población. Asimismo, sostenemos que, de esta forma, se pueden sentar las condiciones para la creación de relatos alternos que ayuden a las comunidades desplazadas a superar su condición de víctima, así como a reconstruir su tejido social y sus identidades en el marco de la experiencia traumática del desplazamiento forzado.

El objetivo es exponer el caso del pueblo de San Marcos, situado en el sur del estado de Sinaloa (noroeste de México), desaparecido bajo las aguas de la presa Picachos, en el que se narrarán las experiencias de los desplazados y las desplazadas en sus procesos de resistencia y reconstrucción de su tejido social y productivo. El periodo de estudio abarca de 2010 a 2012, tiempo en que se realizó el reasentamiento forzoso y los momentos más intensos del movimiento de protesta, con el que los desplazados reclamaban compensaciones justas y medidas de mitigación de los daños.

\section{Antecedentes del caso de estudio}

La presa Picachos forma parte del proyecto hidráulico Baluarte-Presidio en el sur de Sinaloa. Esta zona geográfica se había caracterizado por su rezago en el desarrollo agrícola y la ausencia de grandes embalses. El proyecto de la presa existía desde hace décadas, pero el inicio de la obra se postergó hasta llegar al nuevo siglo. Entonces comenzaron las presiones por desalojar a seis comunidades situadas en el sitio del embalse: San Marcos, La Puerta de San Marcos, Los Copales y El Placer en el municipio de Mazatlán, además de Casas Viejas y Las Iguanas en el municipio de Concordia.

El proceso para informar a la población acerca de la obra y sus consecuencias se caracterizó por su falta de transparencia y por el empleo de amenazas para facilitar el despoblamiento del área, de acuerdo con la narración de la mayoría de los entrevistados. Entre las anomalías, los comuneros demostraron que el Gobierno Federal construyó en los terrenos de su propiedad sin contar con un decreto de expropiación ni la autorización del cambio de uso de suelo correspondiente.

Hasta la fecha (enero de 2017) los terrenos continúan siendo propiedad de los comuneros debido a que no se emitió el decreto de expropiación de los mismos. La Ley Agraria señala que en estos casos los afectados pueden solicitar la restitución de las tierras, lo que equivaldría a la destrucción de la cortina de la represa. Sin embargo, los desplazados sólo piden las indemnizaciones de acuerdo a la ley 
vigente y la implementación de políticas de desarrollo económico para el sustento de las familias que habitaban en los pueblos ahora inundados.

Estos poblados, de donde fueron expulsadas alrededor de 800 familias, contaban con más de 150 años de historia y tradición propias, y una estructura generacional de cuatro a nueve generaciones (Ramírez, 2008, p. 29). La mayoría de sus habitantes se dedicaban a la ganadería, a la agricultura y al comercio con comunidades aledañas. Las tierras bajas junto a los arroyos, las mejores para la siembra, quedarían bajo el agua. Gran parte de esta eran tierras comunales.

La construcción comenzó en 2006; y el éxodo en 2009, cuando al terminar la cortina de la presa y cerrar el túnel de desvío, el agua comenzó a inundar uno a uno los pueblos. Los nuevos pueblos cuya construcción corría a cargo del Gobierno del Estado de Sinaloa - no reunían las condiciones básicas para ser habitables. Las viviendas, sumamente pequeñas en comparación con las casas de los viejos pueblos, aún se encontraban en obra negra. No había escuelas, hospitales ni caminos para ir a las siembras. A pesar de ello, la gente se vio obligada a salir huyendo hacia estos asentamientos improvisados porque muchos de los afectados no contaban con más lugar adónde ir (Guizar, 2009).

La experiencia fue traumática debido a que la tormenta tropical Rick aceleró la relocalización de los habitantes, que se dio en condiciones precarias. En síntesis, el proceso de reubicación se caracterizó por la incertidumbre, el abuso de autoridad y la falta de transparencia. Situación que derivó en acciones públicas de protesta articuladas en un gran movimiento encabezado por comuneros de San Marcos, pero también en diferentes iniciativas legales para exigir indemnizaciones justas y la construcción de pueblos dignos (Guizar, 2009).

Dentro de ese conjunto de acciones, en este artículo se pondrá el foco sobre el movimiento de más impacto social, encabezado por Octavio Atilano Román Tirado, líder de los comuneros de la Presa Picachos, quien tiempo después, el 10 de octubre de 2014, fue asesinado a balazos mientras conducía un programa de radio con el que difundía las acciones del movimiento y busca reforzar la identidad de los pueblos. El crimen de Atilano Román Tirado continúa impune y se suma a la muerte de decenas de activistas y defensores del medio ambiente en México. La gran mayoría aún sin esclarecer.

Como declaró en entrevista Atilano Román, las mujeres fueron “pieza fundamental” de este movimiento en el que ocuparon posiciones de liderazgo y toma de decisiones: “[...Han mostrado más fortaleza que los mismos hombres, las mujeres han salido, son las que menos miedo tienen y se enfrentan ante el gobierno y la Justicia” (entrevista propia, Mazatlán, Sinaloa, a 9 de julio de 2012). Ante la importancia del papel de la mujer en el movimiento, fue necesario incorporar en el proceso investigativo la perspectiva de género como un componente esencial para la comprensión del fenómeno. Se abundará sobre esto en el siguiente apartado, en el que se detallarán las herramientas teóricas y metodológicas que han servido de fundamento para este análisis.

\section{Metodología}

El presente estudio se aborda desde un enfoque cualitativo. Concibe al desplazamiento forzado como un fenómeno complejo en el que intervienen múltiples dimensiones y actores, cuya subjetividad 
resulta determinante para su comprensión debido a que esta forma parte de la construcción social de la realidad. Para recabar la información necesaria, se recurrió a entrevistas semiestructuradas que abordan las distintas etapas del desplazamiento en el tiempo, pero también las motivaciones de los actores sociales dentro de los acontecimientos. Los perfiles de los entrevistados incluyen líderes y lideresas del movimiento, comuneros y avecindados, funcionarios y miembros de la comunidad. Se tomó en cuenta tanto a jóvenes y adultos como a los más ancianos, quienes narraron la historia del viejo San Marcos y las transformaciones a las que se ha sometido con el proceso de relocalización a unos terrenos contiguos que fueron fraccionados con el diseño de un asentamiento urbano.

De igual forma, se procedió a la revisión de los periódicos de cobertura estatal de mayor circulación, El Debate y Noroeste, en cuanto a las notas publicadas acerca del conflicto de 2009 a 2012. Se integraron al análisis las publicaciones de los comuneros en Internet a través del sitio www.picachospueblos.blosgpot.mx y otras en el portal de videos Youtube. El trabajo de observación se realizó en el Nuevo San Marcos durante el periodo de reubicación de las familias, así como en actos de protesta, plantones, marchas y vida cotidiana de los desplazados. El eje analítico es la experiencia de las personas desplazadas y sus subjetividades, dentro de lo cual se le dio un especial énfasis a las categorías de empoderamiento de las mujeres, reorganización colectiva para la resistencia y representaciones sociales de género. Estas se observaron en un plano comparativo del antes y el después del desplazamiento con el objetivo de apreciar continuidades, variabilidad y contrastes.

Por perspectiva de género se entiende lo relativo a "la construcción social de lo masculino y lo femenino" (Lamas, 2005). Lo anterior se traduce en relaciones de desigualdad entre hombres y mujeres, que se hacen efectivas en el control de los cuerpos y las conductas de las personas, quienes deben cumplir determinados roles por el solo hecho de pertenecer biológicamente a uno u otro género. En esta construcción social, las mujeres son objeto de dominación y discriminación, lo que produce el efecto de normalizar la violencia contra ellas en muy variadas formas, desde la violencia económica o simbólica hasta la violencia física, y en su expresión extrema el feminicidio.

El discurso de empoderamiento de los movimientos feministas responde a la necesidad de generar cambios dentro de las relaciones de poder entre géneros, con el fin de lograr la liberación de las mujeres y la construcción de una sociedad más equitativa. Esta retórica cobró auge en los años sesenta, durante la lucha por los derechos civiles en Estados Unidos. A mediados del siguiente decenio se comenzó a utilizar para hablar de las desigualdades sociales entre hombres y mujeres, presentes de manera transversal en diferentes ámbitos y problemáticas, por lo que en ocasiones es difícil detectarlas y se muestran de una forma naturalizada (De León, 1999).

Durante los conflictos sociales, las mujeres se ven afectadas de una manera diferenciada por el rol que se le ha asignado e internalizado social y culturalmente, y salvo casos particulares, las relaciones asimétricas de poder no se modifican en etapas posteriores; al contrario, suelen acentuarse. Por eso consideramos importante describir en qué circunstancias puede ocurrir la condición opuesta, es decir, el empoderamiento de las mujeres dentro de una identidad de resistencia. Al hablar de empoderamiento nos referimos a una noción de poder que trasciende la esfera política formal y abarca el campo social de la vida cotidiana, al acceso a los recursos materiales y culturales de una sociedad, a 
la capacidad de asumir liderazgo e influencia en decisiones públicas y aquellas de corte privado que inciden sobre la calidad de vida a nivel individual. Es un elemento de la estructura social presente en la cotidianeidad al que Foucault (1979) llamaba micropoder, como una manera de distinguirlo del poder del Estado.

En una visión feminista (Oxaal \& Baden, 1997), las estrategias de empoderamiento de las mujeres no significan necesariamente obtener poder sobre otros, en especial sobre los hombres, sino desarrollar sus potencialidades en distintas dimensiones del campo social: poder sobre (para interactuar en conflictos y confrontarse a los poderosos); poder para (desarrollar nuevas habilidades, tomar decisiones y emprender la acción), poder con (crear alianzas y acompañamiento) y poder dentro (incrementar la autoconfianza, la autoestima y el control sobre su propia vida).

A pesar de que el empoderamiento muestra su expresión concreta en el acceso a los recursos materiales y al poder político, es difícil que este pueda presentarse sin el empoderamiento simbólico, una esfera de la vida humana donde tienen lugar las representaciones sociales. Este concepto es tomado de la psicología social para expresar la manera en que los individuos interiorizan la realidad para poder interactuar con ella. De acuerdo con Sergei Moscovici (1979), la idea de representaciones sociales parte de la premisa de que no hay una separación tajante entre el universo exterior y el universo del individuo. Pero este universo no le es accesible de forma absoluta en tiempo y espacio, por lo que el sujeto debe recurrir a una serie de representaciones que se ha creado mentalmente —a través de un proceso de interacción social—, para poder relacionarse con él o intentar aprehenderlo cognitivamente.

Representar es en sentido literal "volver a presentar", como en una obra de teatro, un contenido creado con anterioridad. Así, otra premisa es que por lo general no conocemos la realidad per se, sino sus representaciones. La representación puede entenderse también como el sustituto de una realidad ausente (por eso cuando no podemos estar presentes en algún acto o evento relevante, enviamos a alguien en nuestra representación). Cuando esas representaciones son compartidas por una colectividad las podemos llamar representaciones sociales. Su importancia radica en que motivan la acción humana (individual y colectiva) y le imputan contenidos a las identidades sociales, que pueden ser favorables o desfavorables para los grupos a los que hacen referencia.

En esta lógica, las identidades se conciben como una narración dialógica, que se construye en interacción permanente con los "otros" significativos. La identidad no puede entenderse como una esencia monolítica y constante, sino que varía, cambia, se reconstruye y remodela de acuerdo con las experiencias vividas por los sujetos y por sus luchas, pero al mismo tiempo busca permanecer dentro de un entramado social más amplio en el que interactúa (Giménez, 2007).

Las representaciones sociales de género llevan implícita una carga de valoración que es asociada a un orden social, en el cual mujeres y hombres desempeñan determinados roles, muchas veces como parte de un sistema de dominación inconsciente dentro de la memoria colectiva. En las líneas que siguen veremos cómo en el caso del Nuevo San Marcos, el cambio en las representaciones sociales de género y la reorganización colectiva para la resistencia se encuentran estrechamente ligados al empoderamiento de la mujer dentro del escalamiento de un conflicto y como respuesta a la perturbación de un orden social determinado, como es en este caso el desplazamiento forzado. 


\section{Resultados}

\section{De amas de casa a defensoras del territorio}

Las acciones de protesta del movimiento de "Los Picachos", cuyas principales demandas eran indemnizaciones justas y pueblos dignos, implicaron la reorganización familiar y comunitaria, con lo que el papel de las mujeres se trastocó de forma temporal, pero de manera significativa. Plantones, marchas, tomas de oficinas y manifestaciones tuvieron lugar en la ciudad de Mazatlán y tiempo después también en Culiacán, la capital del estado.

La participación activa en estos actos era una condición para contar con los beneficios del movimiento, como la asignación de terrenos y el pago de indemnizaciones en una estructura clientelar, según las reglas pactadas, por lo que las familias desplazadas debían mostrar su presencia en cada una de las actividades, así que fueron las mujeres quienes tomaron a su cargo la organización de su hogar y de la comunidad. En una situación disruptiva como esta, gran parte de las sanmarqueñas adquirieron una doble responsabilidad: la del trabajo doméstico y la de organización (y acción) para la lucha colectiva. No hubo mucho tiempo para reaccionar a las transformaciones. Pasaron de un discreto papel como amas de casa a ocupar un espacio en los medios de comunicación como defensoras de su territorio (Instituto Nacional de Estadística y Geografía, 2011). Su presencia trascendió en la esfera pública al enfrentarse a los representantes del Estado, al que los comuneros culparon de sacarlos de sus comunidades sin un decreto de expropiación, como establece la Ley Agraria.

El reglamento de la Ley Agraria en materia de ordenamiento de la propiedad rural establece que para la ocupación de terrenos ejidales o comunales es necesaria la expedición de un decreto de expropiación, cuyos requisitos son entre otros, contar con un convenio de los ejidatarios o comuneros de forma previa, así como contar con un presupuesto aprobado para su indemnización. El decreto debe ser refrendado por el titular de la Secretaría de la Reforma Agraria y por el Ejecutivo Federal, y después ser publicado en el Diario Oficial de la Federación. Las condiciones del avalúo e indemnizaciones se exponen en los artículos del 59 al 98 del citado reglamento. Públicamente, el Gobierno del Estado ha reconocido que la obra de la presa Picachos no cuenta con un decreto de expropiación ni con el dictamen de cambio de uso de suelo, bajo la justificación de acelerar el proceso de construcción y conclusión del proyecto.

En este punto es oportuno cuestionarnos ¿qué tanto el rol que ellas jugaron en esta lucha es una continuidad de las relaciones desiguales previas al conflicto? Aquí la respuesta no se dirige en una sola dirección, pues este rol varía dependiendo las necesidades de las movilizaciones y de las múltiples situaciones que han enfrentado a lo largo del tiempo. En primer término, las mujeres soportaron una doble carga al adquirir nuevas responsabilidades sin abandonar sus actividades tradicionales, como las del cuidado de los hijos y del sostenimiento del hogar. Algunas de las actividades de las mujeres dentro de los actos de protesta eran una prolongación de sus labores anteriores, como la de preparar los alimentos y hacer labor de gestión para satisfacer necesidades inmediatas, pero ahora para la comunidad congregada en torno a los actos públicos. 
En sentido opuesto, el rol de las mujeres en la lucha sí representó una discontinuidad con respecto a las funciones que desempeñaban antes del conflicto. Al participar más activamente en la solución de los problemas comunes de sus pueblos, las mujeres tuvieron una mayor influencia en las decisiones que se tomaron en conjunto al interior de la comunidad, y también en la interlocución con el Gobierno del Estado, ya que algunas de las integrantes del movimiento fueron importantes voceras y negociadoras.

Resulta ilustrativo el testimonio de la señora Francisca Valle, quien, a pesar de rebasar los 80 años de edad al momento del desplazamiento, no dudó en participar en las protestas contra el gobierno. Habla aquí de la toma del Congreso del Estado en la capital sinaloense y el plantón en el Palacio de Gobierno, acciones que tomaron lugar después de varios días de marcha multitudinaria por la autopista Culiacán-Mazatlán en marzo de 2010. Para doña Francisca, madre de trece hijos y con toda una vida dedicada a su familia y al campo, resultó satisfactorio el haber podido gritar sus "verdades" a los funcionarios. Recuerda con orgullo que cuando un grupo de señoras inconformes se sentó en el jardín del Palacio de Gobierno, se acercó un empleado para intentar retirarlas.

- Dice el gobernador que se retiren de aquí porque dan muy mal aspecto.

- Dile al gobernador que chingue su madre, que, si nosotros le molestamos en cinco minutos que tenemos aquí, cómo estaremos nosotros que nos quitaron nuestras tierras, y así les gritamos muchas cosas — continuó-; a mí me gusta pelear, pero nomás por lo que es de uno, no pedimos de más. (Entrevista propia, Nuevo San Marcos, Mazatlán, Sinaloa, 10 de abril de 2011).

Francisca Valle asegura no estar en desacuerdo con la construcción de la presa, "pero si las cosas se hubieran hecho bien, si nos hubieran dado unos pueblos como los que teníamos, unas casas como las que teníamos y pagado lo justo, no estaríamos así”. Agrega que las mujeres no se retiraron del plantón. Por el contrario, las manifestaciones de "Los Picachos" continuaron para incomodidad del gobernador, Jesús Aguilar Padilla (2004-2010), y de su sucesor, Mario López Valdez (2010-2016).

La experiencia narrada anteriormente demuestra cómo las mujeres, además de adquirir habilidades para la gestión y organización, también lo hicieron para la confrontación con las autoridades en situaciones que consideran injustas. Dos años después de esa primera marcha, los "Picachos" planearon una nueva caminata por la autopista Mazatlán-Culiacán, pero ahora bloquearían las únicas dos vías existentes en esa ruta, la autopista de peaje y la carretera libre, con lo que se estaría interrumpiendo el tránsito completamente entre estas dos ciudades. Esta decisión fue tomada por los comuneros ante la desesperación de que el Gobierno seguía sin cumplir sus promesas y estaba a punto de concluir la construcción del embalse. Así que mientras bloqueaban la obra se alistaron a marchar de nuevo. Esta vez se enfrentaron al gobierno de Mario López Valdez, quien renunció al PRI (Partido Revolucionario Institucional) para encabezar una coalición electoral que lo llevó al poder y en campaña ofreció apoyo a los desplazados.

El 30 de marzo de 2012 empezó la segunda marcha. A diferencia de 2010, el gobierno estatal usó la fuerza pública. Dos días después, el domingo 1 de abril, al menos 200 agentes de la Policía Estatal Preventiva y la Policía Ministerial disolvieron la manifestación. Según documentó la prensa local, hubo alrededor de cien detenidos, la mayoría hombres, además de decenas de vehículos decomisados. Los 
comuneros denunciaron abusos. Una mujer de alrededor de 50 años nacida en Las Iguanas (uno de los pueblos hundidos bajo la presa), relató su experiencia durante la detención masiva:

- Yo era de las primeras y cuando me dijeron tírese al suelo, yo dije ya me chingué yo fui de las primeras, luego me dijeron 'levántese, señora'; lo que querían era dejar solos a los hombres, luego nos empezaron a quitar los celulares para que nadie tomara fotos... me dijeron quítese señora y yo les decía a los plebes no hagan las cosas más difíciles, nos tienen rodeados, qué les vamos a hacer... mejor tranquilos. ¡Ay!, no, eso fue como que se iba a acabar el mundo...

- Sentí una rabia, una impotencia, cuando vi que agarraron a los hombres y que los llevaban así agarrados del cuello y con las manos para atrás y no poder hacer nada... Y luego cuando ya los tenían en el suelo, los golpearon; pasaba uno y les daba una patada; y luego otro, y otra patada, así se los acabaron a patadas, oiga. Después sentí tan feo, un calor que me recorría el cuerpo porque se habían llevado a mi yerno, pero había otros dos que no estaban detenidos y no aparecían, mi cuñado y mi hermano, ay Dios mío donde están, me los van a matar... No aparecen [...] (Entrevista propia, Nuevo San Marcos, Mazatlán, Sinaloa, 24 de abril de 2012)

Siguiendo el mismo relato, durante la trifulca hubo mujeres cuya reacción fue la confrontación con los agentes policiales:

Y había una señora que no se aguantaba y les gritó de cosas a la policía: "Sí, cómo no agarran a los secuestradores a los asesinos, a esos no los agarran porque les tienen miedo, ¿verdad? Pero vienen contra nosotros que nada les hemos hecho, son unos sinvergüenzas igual que todos los del gobierno, por eso están en el gobierno, porque son unos rateros, los más rateros son los del gobierno". Y les dio coraje.

—Cállese, señora.

-No me callo.

-Pues me la voy a llevar.

—Pues llévame, le dijo

- Pues llévanos a todas les dijo otra señora, al menos ahí en la cárcel me van a tener que dar de comer, porque acá en mi tierra ya no puedo ni sembrar porque el gobierno me robó todo...(Entrevista propia, Nuevo San Marcos, Mazatlán, Sinaloa, 24 de abril de 2012)

Después de este acto represivo, las mujeres que quedaron en libertad estaban separadas en dos contingentes, uno en cada una de las rúas bloqueadas, y entraron en desesperación. Decidieron tomar los pocos carros que no habían sido incautados y perseguir a las patrullas para verificar hacia dónde llevaban a los detenidos, pues temían fueran violentados o desaparecidos. A los días siguientes liberaron a la gran mayoría, pero retuvieron a cuatro líderes: Octavio Atilano Román Tirado, Óscar René Osuna Díaz, Hortensia Gutiérrez Zamora y José Isabel Osuna Lizárraga. Este tiempo, María José Osuna Gutiérrez, hija de Hortensia Gutiérrez, pasó a ser la nueva vocera del movimiento.

Enseguida se emprendió una movilización para exigir la liberación de los dirigentes a quienes catalogaban como presos políticos. Un plantón en el ayuntamiento de Mazatlán, otro en la sede de las oficinas de la Procuraduría de Justicia en Culiacán, así como una marcha por el malecón del puerto 
mazatleco fueron las acciones emprendidas a las que se unieron representantes de organismos ciudadanos. Después de 17 días de una batalla legal y mediática, los dirigentes fueron puestos en libertad y aseguraron que la lucha continuaría.

Obligadas por las circunstancias, debido a que en las acciones de represión por parte del gobierno los hombres sufrían el impacto directo al ser golpeados o encarcelados, las mujeres adoptaron el papel de interlocutoras, gestoras y de confrontación para poder lograr la permanencia de la comunidad, que no sólo se vio amenazada por la destrucción de sus antiguos pueblos, sino después con una racha de violencia sucedida entre septiembre de 2010 y mediados de 2011 en la que decenas de personas, la mayoría hombres, perdieron la vida a manos de grupos armados o fueron desaparecidas forzadamente.

El número de víctimas se calculó con base en recuentos de los propios entrevistados y de publicaciones periodísticas acerca de los homicidios ocurridos en los pueblos aledaños a San Marcos en el municipio de Mazatlán, con el que han sostenido una interacción muy intensa tanto en lo familiar como en lo comercial a lo largo de varias décadas, como son los pueblos de La Noria, El Tecomate de La Noria, La Palma Sola, Puerta de Canoas y otros más.

En este periodo, parte de los desplazados se encontraba en los nuevos pueblos y otra parte había migrado a la ciudad de Mazatlán en busca de adaptarse a su nueva realidad. Todo Sinaloa, y en especial las zonas rurales, padecían las consecuencias de la guerra contra el narcotráfico declarada por el Presidente Felipe Calderón (2006-2012) o de las pugnas por territorio entre bandas rivales. Y las inmediaciones de San Marcos no eran libres de esta amenaza, sin embargo, los desplazados denunciaban constantemente que la mano de Gobierno del Estado los acechaba en represalia por haber iniciado el movimiento de protesta. En este escenario, las mujeres enfrentaron la violencia con mayor responsabilidad en sus hogares, pero sin descuidar la batalla contra el gobierno.

Originaria de San Marcos al igual que sus padres y abuelos, María Ascención Moreno Enciso asegura que la lucha social tras el desplazamiento forzoso ha estado llena de aprendizajes. Comparte su opinión al mismo tiempo que muestra una serie de recortes de periódico donde se publican noticias y crónicas acerca de la historia de "Los Picachos". También algunos donde ella aparece en fotografías, portando pancartas o marchando bajo el rayo del sol:

Hemos aprendido a no dejarnos, que si no luchamos no se nos van a respetar nuestros derechos, ya no somos tan calladas, antes las mujeres nomás en su casa, ahora no nos da miedo enfrentarnos al gobierno; decían 'las mujeres al frente' y nunca nos dio miedo [...] A mí me gustaría que mis nietos supieran que su abuela luchó por lo suyo, por el patrimonio de la familia, para que ellos tampoco se dejen. (Entrevista propia, San Marcos, Mazatlán, Sinaloa, 18 de julio de 2012)

No todas las mujeres desplazadas se unieron a las movilizaciones, pero quienes sí lo hicieron muchas de ellas propietarias de terrenos en los pueblos inundados-, coincidieron en que hubo más ganancias que pérdidas al momento de optar por la lucha social, en comparación de haber aceptado lo que el gobierno ofrecía a los afectados. No se hubieran construido nuevos pueblos y las indemnizaciones hubieran sido raquíticas, sin tomar en cuenta los bienes colectivos. Los testimonios 
de las mujeres reflejan ganancias adicionales de tipo subjetivo como la adquisición de capacidades para la gestión, la organización colectiva, la resistencia y un sentido de dignidad que supera la condición de víctima tanto dentro como hacia fuera de la comunidad.

\section{Desplazadas y líderes: nueva representación en los medios}

La secuencia de acciones de "Los Picachos" incluye una larga lista de marchas, plantones, manifestaciones, tomas simbólicas de oficinas públicas, hasta la procesión de los comuneros con sus muertos en el paseo costero y una marcha en el desfile del Carnaval de Mazatlán en 2010 (Guizar, Llevan comuneros protesta al Carnaval, 2010). En todas ellas sobresalieron las mujeres al frente del movimiento y la prensa local dio una puntual cobertura a todo lo relacionado con este conflicto, con lo que las mujeres desplazadas adquirieron notoriedad pública.

Desde la perspectiva de este trabajo, la información publicada en periódicos, sitios de internet, redes sociales, cinematografía y otros medios de comunicación contribuyó a la construcción de narrativas alternas acerca de las representaciones sociales de género en el caso de las mujeres desplazadas por la presa Picachos. En el imaginario colectivo de esta región de Sinaloa, un estado célebre por las masculinidades exacerbadas asociadas al narcotráfico, surgieron heroínas defensoras de su territorio caracterizadas por su tenacidad, sentido de justicia y capacidades para influir sobre el destino de sus comunidades.

Abundaron imágenes donde las mujeres eran protagonistas. Una de las más significativas fue captada el 13 de julio de 2009, en una de las acciones que marcó el inicio del movimiento (Guizar, Desalojan la presa Picachos, 2009). Desde inicios de ese año, decenas de comuneros habían tomado la presa para impedir el cierre del túnel de desvío y con esto evitar la inundación de sus pueblos, pero al gobierno estatal le urgía entregar la obra para evitar demandas legales por parte de la constructora y una cuantiosa sanción. El desalojo con uso de la fuerza pública era inminente. Más de cien elementos de la Policía Federal Preventiva y de la Policía Estatal Preventiva utilizaron toletes, escudos antimotines y bombas de gas lacrimógeno para lograr este objetivo.

A la par de los hombres, las mujeres se carearon con los policías y opusieron resistencia, aunque finalmente los comuneros fueron retirados con el saldo de algunos heridos y seis detenidos (Guizar, Desalojan la presa Picachos, 2009). En las imágenes del periódico Noroeste se puede observar cómo las mujeres empujan los escudos de los agentes, algunas de ellas con niños en los brazos, con lo que demostraron no tener miedo. A partir de entonces las protestas subirían de intensidad, pues con el cierre del túnel de desvío y el comienzo de la temporada de lluvias, en cualquier momento los pueblos comenzarían a inundarse para siempre.

En el transcurso de las manifestaciones eran las mujeres las que planeaban las acciones para generar un mayor impacto en la opinión pública al utilizar elementos simbólicos que le dieran un sentido de identidad a cada protesta. Por ejemplo, el día en que tomaron simbólicamente el aeropuerto internacional de Mazatlán, General Rafael Buelna Tenorio, encarando con flores a los granaderos enviados para contener la manifestación; o el día en que marcharon con sus muertos por todo el 
malecón de Mazatlán en exigencia de un nuevo lugar para el descanso eterno de sus seres queridos, debido a que los camposantos de sus pueblos habían quedado bajo las aguas del embalse.

Hasta entonces, en el imaginario colectivo de la comunidad de San Marcos y pueblos aledaños sólo existían corridos para los "machos", envalentonados, diestros para la pistola y veloces para la fuga a lomo de bestia; en la ficticia galería de los héroes sólo había espacio para los hombres. El movimiento de los desplazados de la presa Picachos no sólo se gestó a través de liderazgos femeninos, como el de Rosario Alapizco, conocida como "Charis", o el de Hortensia Gutiérrez y su hija, María José Osuna Gutiérrez, sino que también generó una narrativa popular conformada de heroínas, cuyo principal mérito era defender el territorio con valentía y honestidad.

\section{Corridos y heroínas: de "Los del Monte" a "las de Picachos"}

En San Marcos, los antecedentes de un movimiento de lucha en defensa del territorio se remontan a los tiempos del cardenismo (1934-1940). Los rancheros del sur de Sinaloa, comandados por la familia Tirado Osuna que había amasado una pequeña fortuna con el negocio de vinatería, se aliaron a gavilleros que para entonces operaban en la sierra en grupos dispersos y conformaron un ejército que ofreció una brutal resistencia a la Reforma Agraria. Los Tirado eran originarios de la Palma Sola, una ranchería situada junto al viejo San Marcos con el que mantenían intensa comunicación. En la Palma Sola nació Manuel Sandoval "El Culichi”, cabecilla de un grupo de alzados a quienes se les conoció como "Los del Monte" por su habilidad de moverse en los vericuetos de la serranía (de acuerdo con la historia oral recogida en las entrevistas con las personas más longevas del pueblo).

A unos cuantos kilómetros de allí, por los rumbos del poblado de Puerta de Canoas, vivían los hermanos José María y Pedro Ibarra, que también andaban armados y se oponían al agrarismo. Mientras tanto, hacia el noreste operaba otro bandolero, Rodolfo Valdez Valdez "El Gitano", nacido en Aguacaliente de Gárate (una localidad del vecino municipio de Concordia), quien pasó a la historia como el asesino del gobernador de Sinaloa en 1944, Rodolfo T. Loaiza. Aunque la historia oficial los coloca como bandidos y asesinos, en la memoria colectiva de estos pueblos se reivindican como héroes populares que lucharon por una causa justa: la defensa de su tierra.

En las entrevistas tanto a los más longevos del viejo San Marcos como a los jóvenes, se puede observar el sentido de admiración hacia estos personajes que se levantaron en armas y, a pesar de sus fechorías, mantenían límites de respeto hacia la comunidad, como el "no matar sin motivo", o el "respetar a mujeres y niños".

En la historia oral de los sanmarqueños, sobresalen las hazañas de "El Culichi", quien fue largamente perseguido por el Gobierno y gracias a su astucia nunca pudo ser aprehendido. A pesar de su larga trayectoria de bandolero, pues se dice que empezó desde adolescente, jamás recibió un balazo

y falleció poco después de los 50 años de edad a causa del asma. Los habitantes de San Marcos pensaban que gozaba de una ayuda sobrenatural para escapar de sus enemigos. 
Esto es parte de lo que narra don Irenio Lizárraga Sánchez, quien hace las veces de cronista del pueblo, aunque sin nombramiento oficial. (Entrevista propia, 24 de febrero de 2012, Nuevo San Marcos, Mazatlán, Sinaloa. Al momento de la entrevista, contaba con 93 años de edad).

Nombrados también como "los valientes", los relatos acerca de estos hombres armados, a caballo y desafiantes a la autoridad del gobierno, van desde las derrotas que infligían al Ejército hasta sus pleitos de cantina por una mujer o de cómo las muchachas se morían por bailar con ellos en las fiestas del pueblo. El "Corrido del Gitano" es uno de tantos que exaltan estas cualidades en los hombres que defendieron las tierras de lo que consideraban una repartición agraria injusta, como se aprecia en el siguiente fragmento:

Voy a cantar un corrido Año del 63 En Culiacán, Sinaloa murió Rodolfo Valdez La pequeña propiedad era lo que defendía Como dorado el Gitano rondaba de noche y día Al lado de Pedro Ibarra Por el año 37 comenzó sus correrías el guerrillero valiente (...) (Castillo, F, 2000)

Cualidades como la valentía, la fuerza y la astucia eran atribuidas casi exclusivamente al género masculino. Los hombres eran los únicos facultados para la guerra. En contraste, las menciones sobre el papel de la mujer en la comunidad se remiten a sus tareas domésticas, su papel de madres, esposas e hijas. Pero la mayoría de las veces ni siquiera es mencionada.

Esta revuelta armada provocó una gran devastación en el sur de Sinaloa, una guerra civil con pueblos arrasados, desplazamientos forzosos y cientos de muertos, que permanece en la memoria colectiva de las comunidades (Aguilar, 1997); (García Cabrera, 2012). Más de seis décadas después, un nuevo conflicto sacude al viejo San Marcos. También es por la tierra, pero ahora las condiciones sociales son distintas. También el lugar que ocuparon los liderazgos femeninos en el movimiento de protesta y en la comunidad.

Siguiendo la tradición popular, no faltaron corridos para preservar en la memoria colectiva este nuevo capítulo de la lucha de un pueblo por su territorio. Pero a diferencia de la historia del antiagrarismo, alimentada de las hazañas de los hombres "valientes", surgieron heroínas que saltaron a la escena pública. Como ejemplo, tenemos el corrido compuesto por Hortensia Gutiérrez dedicado a la comunidad de Las Iguanas, de donde es originaria Rosario Alapizco, una de las primeras interlocutoras con el Gobierno del Estado para negociar beneficios para los pueblos desplazados y a quien se describe como una mujer de lucha y de causas justas, lo que se puede apreciar en la siguiente estrofa que fue proporcionada por su compositora y autora:

En ese pueblo nació una mujer muy entera, es una mujer de lucha que no respetó frontera y hasta en Estados Unidos luchó como una fiera Rosario, nombre de pila, conocida como Charis, los de la presa Picachos, ahí todo el mundo sabe que tiene muchas agallas y no se le raja a nadie. Ahí en la presa 
Picachos hay mujeres muy valientes comenzando con la Félix, por ella se queda al frente, y así son las de Picachos saben muy bien defenderse.

Los héroes — como las heroínas - sincretizan los anhelos y valores de un pueblo y poseen la cualidad de encausarlo en pos de un objetivo común, y por lo mismo son susceptibles a la imitación por parte de los demás miembros del colectivo. Estas características no se relacionaban sólo con las mujeres líderes, sino con las mujeres en general. Por ello, hacia el final del estribillo, el corrido mencionado generaliza y establece que "las mujeres de Picachos saben muy bien defenderse".

Durante las movilizaciones en contra de la presa Picachos, las mujeres sobresalieron por su irreverencia y por hacer uso del sarcasmo en su discurso, lo que logró en incontables ocasiones atraer la atención de periodistas y ciudadanos, y al parecer también el encono de los gobernantes ante el franco reto a su autoridad.

En el corrido La Diablita, interpretado por las Hermanitas Aguirre, un dueto conformado por mujeres oriundas de la sindicatura de La Noria (al que pertenece San Marcos) del municipio de Mazatlán, se enfatiza el lenguaje transgresor pero también la forma en que un pueblo inconforme puede convertirse en una pesadilla, en la encarnación del mal para el gobierno que el pueblo ha catalogado como enemigo, en un demonio con rostro de mujer, aunque sólo sea en el plano de lo simbólico:

Allá por las Olas altas del puerto de Mazatlán la Diablita se aparece empezando el carnaval, recordándole al gobierno lo que tiene que pagar. La Diablita le bailaba recordándole al gobierno: si no me pagas las tierras te llevaré hasta el infierno porque tú vas a soñarme hasta en tus más lindos sueños. (Producción independiente de las Hermanitas Aguirre, originarias de la sindicatura de La Noria, municipio de Mazatlán).

Una de las intérpretes, Blanca Aguirre, asegura que dedica la canción al entonces gobernador Mario López Valdez, quien después de diez meses en el gobierno (hasta septiembre de 2011) no había cumplido sus promesas de campaña. “[...] ¿Dónde está lo que usted nos prometió; toda la Picachos estamos muy, ahora sí como se dice vulgarmente, muy encabronadas; ¿por qué? Porque de puras promesas... ya está como la canción de Daniela Romo, 'promete y promete y nada cumple'. ¿Dónde está? Ya son diez meses los que tiene en el poder, y ¿dónde está'. Todos nuestros hijos tienen hambre, no hay escuelas, no hay calles, no hay nada. Todas las personas de la tercera edad las están dejando, las dejaron, sin patrimonio. ¿Qué vamos a hacer?”, declaró Blanca Aguirre en un video publicado en el portal Youtube luego de interpretar "La Diablita". 
Con estos ejemplos, vemos cómo las mujeres no fueron sólo temática de los nuevos corridos, sino que asumieron el papel de compositoras, intérpretes y productoras de este género musical, que no sólo puede ser analizado en función de su estructura lírica, sino como un fenómeno sociohistórico que es reflejo del sistema de valores de una sociedad (Lira-Hernández, 2013). Siguiendo este enfoque, el giro en los corridos inspirados en la historia del viejo San Marcos denota un cambio en las representaciones sociales de género, que podría representar algunas consecuencias en la estructura social, aunque llegar a este tipo de conclusión amerita la realización de nuevas investigaciones.

\section{De lo simbólico a lo material: a manera de epílogo}

Entre la estrategia jurídica y el movimiento de protesta, que se llevaban de forma paralela, los desplazados obtuvieron la construcción de los seis nuevos pueblos en terrenos aledaños a la presa Picachos. Para 2014, la mayoría de los pueblos contaban con carreteras, escuelas y hospitales, si bien eso no terminaba de resolver el problema social y económico a falta de oportunidades de trabajo. Las tierras inundadas eran las más viables para la agricultura y la ganadería, en este sector el número de empleos disminuyó drásticamente. Entonces se optó por buscar nuevas fuentes de trabajo. Una de las exigencias fue que las familias desplazadas fueran las primeras en ser beneficiadas por las actividades que se pudieran realizar en el embalse de la presa, que además de ofrecer un bello paisaje, cuenta con el potencial de explotar el turismo y la pesca deportiva.

Con ese propósito se formaron cooperativas para el cultivo de tilapia para beneficio de al menos 200 familias. También la construcción de un restaurante y de por lo menos 28 cabañas que dan alojamiento a turistas y pescadores deportivos (Regalado , 2016). En la transición de pueblos campesinos a destino turístico, las comunidades desplazadas han incorporado tanto a hombres como mujeres. En las capturas de tilapia predomina la participación masculina; y en la atención del restaurante y de la preparación de los productos de la presa, la del género femenino. Una buena parte de los pobladores migró a la ciudad, en especial al puerto de Mazatlán donde, de acuerdo con los testimonios, algunos se instalaron en colonias de la periferia viviendo de trabajos precarios y otros invirtieron parte de los pagos compensatorios en pequeños negocios comerciales.

No se cuenta con estudios que nos indiquen si en el largo plazo el empoderamiento simbólico que se vio en las mujeres desplazadas durante la coyuntura del reasentamiento, se traslada a otros ámbitos como el de la economía o la participación política. Sin embargo, en el seguimiento del caso, resulta significativo que, desde junio del 2015, sea una mujer la presidenta de la comunidad de San Marcos, Adriana Gutiérrez Enciso, elegida por la vía democrática para continuar con la gestión de pagos de indemnización pendientes y con los esfuerzos para hacer crecer los rendimientos de la pesca y el turismo. En la elección para renovar el comisariado de la comunidad de San Marcos, Adriana

Gutiérrez Enciso resultó triunfadora por 69 votos contra 51. Véase: Zataráin, L., 2015. Eligen nuevo dirigente y mesa directiva de Los Picachos. 


\section{Conclusiones}

La historia del movimiento de los desplazados por la presa Picachos nos arroja una serie de reflexiones acerca de las estrategias que adoptan los pueblos cuando se ven afectados por fuerzas disruptivas de su entorno, como es el fenómeno del desplazamiento forzado.

En este caso provocado por la construcción de una obra de desarrollo, que en contravía de la normatividad vigente, carecía de planes de desarrollo económico y social para la recuperación de la calidad de vida de las personas afectadas.

Como vimos, algunas acciones de restitución y de construcción de nuevos pueblos fueron implementadas sólo bajo la presión de las movilizaciones de protesta.

Los pobladores desplazados por la presa Picachos en el sur de Sinaloa se vieron obligados no sólo a la relocalización en condiciones de precariedad, sino también a la reconstrucción de su vida social, lo que representó la adquisición de nuevas maneras de organización durante la coyuntura del conflicto y el proceso de reasentamiento.

Dentro de esta experiencia, jugaron un papel determinante el replanteamiento de roles de género y la construcción de nuevas representaciones sociales acerca de las mujeres, quienes, a diferencia del pasado, presentaron una presencia más activa en la vida pública de su comunidad y tomaron decisiones que influyeron en las negociaciones del movimiento, pero también de los pueblos en su conjunto.

Aparecieron las mujeres que negociaron las indemnizaciones con las autoridades civiles, pero también aquellas que confrontaron a la fuerza pública y las que supieron tejer alianzas con otros sectores de la sociedad civil.

En las narraciones de las entrevistadas sobresale la ampliación de su repertorio de estrategias de vida, que coinciden con la clasificación de Oxaal y Baden (1997).

El empoderamiento que se observa en las mujeres, al menos de manera coyuntural, se relaciona con el poder sobre al participar en la resolución de conflictos y negociar con los representantes del poder formal; con el poder para con el desarrollo de nuevas habilidades como la gestión, la creación de estrategias, la resistencia civil; con el poder con al mostrar la capacidad de organización y la concreción de alianzas; y con el poder dentro al aumentar la confianza en sí mismas para alcanzar objetivos que no sólo tienen que ver con su vida privada sino con la colectividad. 


\section{Referencias Bibliográficas}

Aguilar Alvarado, M. (1997). La política agrícola y agraria en Sinaloa de 1920 a 1940. Revista Clío, 131-148. Recuperado de:

http://historia.uasnet.mx/rev\%7B_\%7Dclio/Revista\%7B_\%7Dclio/Revista18/7\%7B_\%7DP ol\%7B_\%7DAguilar.pdf

Castillo, F. (2011). Corrido del Gitano. Youtube. Recuperado de: https://www.youtube.com/watch?v=ORsyA3jo_24.

De León, M. (1999). Poder y empoderamiento de las mujeres. Región y Sociedad, XI (18), pp.189_ 197. Recuperado de: http://lanic.utexas.edu/project/etext/colson/18/18_8.pdf.

Foucault, M. (1979). Microfísica del poder 2nd ed., Madrid: Las ediciones de la Piqueta. Recuperado de: http://www.inau.gub.uy/biblioteca/seminario/microfisica.

García Cabrera, J. L. (2012). El Pastel (parte uno). Sinaloa: Jose Luis Garcia Cabrera. Obtenido de https:/ /books.google.com.mx/books?id=7XtbAAAAQBAJ\&pg=PA1950\&lpg=PA1950\&dq= guardias + blancas $+\% 2 \mathrm{~B}+$ sur + de + sinaloa\&source $=$ bl\&ots $=$ vDTJdT1xBn\&sig $=V 3 B W O 3 z v P$ BuILA0ik_6W6ngEMOg\&hl=es419\&sa $=$ X\&ved=0ahUKEwilq82sgYbSAhXKqVQKHfqXCUcQ6AEIJzAC\#v = onepage\&q= guardias $\% 20$ blan

Giménez, G. (2007). Estudios sobre la cultura y las identidades sociales Primera., México, DF:

CONACULTA. Recuperado de: https://filosinsentido.files.wordpress.com/2013/07/gilbertogimc3a9nez-estudios-sobre-la-cultura-y-las-identidades-sociales.pdf.

Guizar, M. (14 de julio de 2009). Desalojan la presa Picachos. Obtenido de noroeste.com.mx: http://www.noroeste.com.mx/pub/151810

Guizar, M. (31 de diciembre de 2009). Presa Picachos: Cambio de pueblos. Obtenido de noroeste.com.mx: http:/ /www.noroeste.com.mx/pub/202918

Guizar, M. (15 de febrero de 2010). Llevan comuneros protesta al Carnaval. Obtenido de noroeste.com.mx: http://www.noroeste.com.mx/pub/216174

Instituto Nacional de Estadística y Geografía. (20 de febrero de 2011). Censo de Población y Vivienda 2010. Obtenido de Instituto Nacional de Estadística y Geografía (INEGI)-Mexico: http:/ /www.inegi.org.mx/sistemas/consulta_resultados/iter2010.aspx?c=27329\&s=est

Lira-Hernández, A. (2013). El corrido mexicano: un fenómeno histórico-social y literario. Contribuciones desde Coatepec, Enero-juni(24), pp.29-43. Recuperado de: http:/ /www.redalyc.org/pdf/281/28126456004.pdf.

Moscovici, S. (1979). La representación social: un concepto perdido. In El psicoanálisis, su imagen y su público. Buenos Aires: Huemul, pp. 27-44. Recuperado de:

http://www.cholonautas.edu.pe/modulo/upload/tallmosc.pdf.

Olaya Rodriguez, C. (2015). Conflictos socio-ambientalesen el Oriente Antioqueño. Kavilando, 15-21. Olaya Rodriguez, C. (2016). Justicia ambiental: que las aguas fluyan hacia la Paz. Kavilando, 8(2), 30 -

40. Obtenido de http://www.kavilando.org/revista/index.php/kavilando/index

Oxaal, Zöe y Baden, S. (1997). Gender and empowerment: definitions, approaches and implications for policy, Brighton, UK. Recuperado de:

http://www.bridge.ids.ac.uk/sites/bridge.ids.ac.uk/files/reports/re40c.pdf. 
Ramírez López, J.A. (2008). La construcción de la presa Picachos: una visión históricosocioambiental Primera ed., Mazatlán, Sinaloa: Conacyt, Cetmar y DGEPyTM.

Regalado , B. (2016). Cabañas presa Picachos, un lugar para descansar y pescar. Obtenido de Periodico El Debate: http://www.debate.com.mx/mazatlan/Cabanas-Presa-Picachos-unrincon-para-descansar-y-pescar-20160429-0116.html

Villa Gomes, J., \& Insuasty Rodriguez, A. (2016). Entre la participación y la resistencia: reconstrucción del tejido social desde abajo, más allá de la lógica de reparación estatal. El Agora USB, 16(2). Obtenido de http://revistas.usb.edu.co/index.php/Agora/index

Villaseñor Farías, M. (2003). Masculinidad, sexualidad, poder y violencia: análisis de significados en adolescentes. Salud pública de México, 45(1), pp.44-57. Recuperado de: http:/ /www.scielo.org.mx/scielo.php?script=sci $\left\{\_\right\} \operatorname{arttext}\{\&\}$ pid=S003636342003000700008.

World Comission on Dams. (2000). Represas y desarrollo. Un nuevo marco para la toma de decisiones, Recuperado de: https://www.internationalrivers.org/files/attachedfiles/wcd_espanol.pdf.

\section{Notas:}

${ }^{i}$ Este artículo forma parte de la tesis de maestría "La reconstrucción de la identidad socioterritorial tras el desplazamiento provocado por la presa Picachos. El caso del Nuevo San Marcos”, presentada por la autora el 23 de noviembre de 2012 en la Facultad de Ciencias Sociales de la Universidad Autónoma de Sinaloa unidad Mazatlán. 